Gastrointestinal symptoms were not prominent, and the excess in girls mirrors that seen in affected adults. The most striking observation was that children with IgA-EMA were shorter by more than 0.76 standard deviation scores and lighter by 0.54 standard deviation scores than antibody negative children matched for date and place of birth. This equates to about 9 months' growth and weight gain in an average child around this age. These features were independent of gastrointestinal symptoms and anaemia and presumably unrelated to malabsorption.

Occult coeliac disease seems to start in childhood, even in those who are subsequently diagnosed as adults. The search for the trigger resulting in the breakdown of immune tolerance to gluten therefore needs to focus on infancy and intrauterine life.

We thank the children and their families taking part in the study for their continuing support and the midwives for their cooperation and help in recruitment. The ALSPAC study team comprised interviewers, computer technicians, clerical workers, research scientists, volunteers, and managers who continue to make the study possible.

Contributors: PJB, DJU, and AJKW designed the study with members of the ALSPAC study team. AJKW, RJL, and AJN developed and completed all antibody assays. RWJ coordinated the collection of biological samples and supervised handling of the samples. PJB analysed and interpreted the data with help from ARN. PJB wrote the report with help from the other authors. PJB is guarantor.

Funding: Coeliac UK, Medical Research Council, Wellcome Trust, UK government departments, and various charitable organisations and commercial companies. ALSPAC is part of the WHO initiated European Longitudinal Study of Pregnancy and Childhood.

Competing interests: None declared.

Ethical approval: ALSPAC ethics and law committee and local ethical research committees.

1 Hawkes ND, Swift GL, Smith PM, Jenkins HR. Incidence and presentation of coeliac disease in South Glamorgan. Eur J Gastroenterol Hepatol 2000; $12: 345-9$.

2 Maki M, Mustalahti K, Kokkonen J, Kulmala P, Haapalahti M, Karttunen $\mathrm{T}$, et al. Prevalence of celiac disease among children in Finland. $N$ Engl $J$ Med 2003;348:2517-24.

3 Golding J, Pembrey M, Jones R, ALSPAC study team. ALSPAC: the Avon longitudinal study of parents and children. I. Study methodology. Paediatr Perinat Epidemiol 2001;15:74-87.

4 Bazzigaluppi E, Lampasona V, Barera G, Venerando A, Bianchi C, Chiumello $\mathrm{G}$, et al Comparison of tissue transolutaminase-specific antiCho 1999;12:51-6.

5 West J, Logan RF, Hill PG, Lloyd A, Lewis S, Hubbard R, et al. Seroprevalence, correlates, and characteristics of undetected coeliac disease in England. Gut 2003;52:960-5

(Accepted 11 September 2003)

\title{
Use of tobacco products as dentifrice among adolescents in India: questionnaire study
}

\author{
D N Sinha, P C Gupta, M S Pednekar
}

In India legislation prohibits the use of tobacco as an ingredient in dental care products. ${ }^{1}$ Such products, in the form of powder or paste, are applied most commonly with the index finger to teeth and gums. Various tobacco products are used as dentifrice in different parts of India. ${ }^{2}{ }^{3}$ We are not aware of any reports covering such a use of tobacco products (in contrast to chewing and smoking) especially among adolescents. ${ }^{45}$

\section{Participants, methods, and results}

The global youth tobacco survey focuses on school students aged 13-15 and uses standardised methods. ${ }^{4}$ In India the survey is being conducted independently in each state. We report on the prevalence of the use of tobacco products as dentifrice in 14 states listed in the table, with sample sizes ranging from 2067 to 5245 students.

We selected a two stage probability sample of students in grade 8-10 (which corresponds to 13-15 years in age) in each state and conducted a survey among students with an anonymous, self administered, close ended questionnaire. Participants were asked to include a maximum of five products, which could differ from state to state. A pilot tested questionnaire for India contained a specific question on application of tobacco products (in addition to chewing), and a positive response identified the use of a tobacco product as dentifrice. We defined current use as use within 30 days preceding the survey.
The overall response rate was over $80 \%$ except in Bihar (70\%) and Maharashtra (79\%). The proportion of boys was between $50 \%$ and $55 \%$ in the different states.

The use of tobacco products as dentrifice varied from $6 \%$ (Goa) to $68 \%$ (Bihar). The prevalence among boys was notably higher than among girls in Orissa and Uttaranchal, marginally higher in nine states, and marginally lower in three states. Of the specific products, tobacco toothpaste (creamy snuff) and tooth powder (lal dant manjan) were common in all states (table). Gul (a pyrolysed tobacco product) was used in eight states. Other dentifrice products containing tobacco were: mishri (roasted and powdered tobacco) and dry snuff (bajjar or tapkir) in Goa and Maharashtra; gudakhu (paste of tobacco and molasses) in Bihar, Orissa, Uttar Pradesh, and Uttaranchal; and tobacco water (tuibur or hidakphu, manufactured by passing tobacco smoke through water) in Manipur, Mizoram, Sikkim, and Tripura. It is used for gargling, not drinking.

\section{Comment}

Many students in India use tobacco products as dentifrice. Differences between the sexes were minimal and similar to those reported globally. ${ }^{5}$

In India the misconception is widespread that tobacco is good for the teeth. In a study reported from Ernakulam district in Kerala 92\% (3013) of 3261 female
School of

Preventive Oncology, A127 Anandpuri, Boring Canal Road, Patna 800001, India D N Sinha chairman

Tata Institute of Fundamental Research, Homi Bhabha Road, Colaba, Mumbai 400005 , India P C Gupta senior research scientist

Epidemiology Research Centre, Tata Memorial Centre, Ernest Borges Marg, Parel, Mumbai 400012, India

M S Pednekar senior statistician

Correspondence to: P C Gupta pcgupta@tifr.res.in

BMJ 2004;328:323-4 
Prevalence of application of tobacco products as dentifrice: results from the global youth tobacco survey in 14 states, in India, 2000-2. Values are percentages (95\% confidence intervals)

\begin{tabular}{lcccc} 
State (sample size) & Toothpaste & Gul & Tooth powder & Others \\
\hline Arunachal Pradesh $(\mathrm{n}=2314)$ & $23(18$ to 27$)$ & $2(1$ to 3$)$ & $4(2$ to 5$)$ & - \\
\hline Assam $(\mathrm{n}=2177)$ & $11(9$ to 14$)$ & $3(1$ to 5$)$ & $4(3$ to 6$)$ & - \\
\hline Bihar $(\mathrm{n}=2636)$ & $10(7$ to 12$)$ & $6(4$ to 7$)$ & $49(43$ to 54$)$ & $4(3$ to 6$)$ \\
\hline Goa $(\mathrm{n}=2256)$ & $2(1$ to 2$)$ & - & $2(1$ to 2$)$ & $3(2$ to 4$)$ \\
\hline Maharashtra $(\mathrm{n}=2356)$ & $2(1$ to 3$)$ & - & $2(1$ to 3$)$ & $9(7$ to 12$)$ \\
\hline Manipur $(\mathrm{n}=1734$ & $25(22$ to 28$)$ & - & $2(0$ to 3$)$ & $5(1$ to 9$)$ \\
\hline Meghalaya $(\mathrm{n}=2080)$ & $18(12$ to 25$)$ & $1(0$ to 1$)$ & $4(2$ to 5$)$ & - \\
\hline Mizoram $(\mathrm{n}=2295)$ & $12(9$ to 15$)$ & - & $9(6$ to 12$)$ & $4(2$ to 7$)$ \\
\hline Nagaland $(\mathrm{n}=2221)$ & $32(23$ to 40$)$ & $3(2$ to 4$)$ & $5(4$ to 7$)$ & - \\
\hline Orissa $(\mathrm{n}=2913)$ & $10(8$ to 12$)$ & $1(1$ to 2$)$ & $25(23$ to 28$)$ & $4(2$ to 6$)$ \\
\hline Sikkim $(\mathrm{n}=2236)$ & $8(5$ to 11$)$ & - & $2(1$ to 3$)$ & $1(1$ to 1$)$ \\
\hline Tripura $(\mathrm{n}=1866)$ & $25(19$ to 31$)$ & - & $3(1$ to 4$)$ & $1(1$ to 2$)$ \\
\hline Uttar Pradesh $(\mathrm{n}=4542)$ & $10(8$ to 12$)$ & $2(1$ to 3$)$ & $29(24$ to 33$)$ & $16(9$ to 22$)$ \\
\hline Uttaranchal $(n=2642)$ & $18(14$ to 21$)$ & $2(1$ to 3$)$ & $29(26$ to 32$)$ & $11(5$ to 16$)$ \\
\hline
\end{tabular}

tobacco users and 28\% (2159) of 7575 male users specified tooth related problems as the reason for starting to use tobacco. ${ }^{3}$ Many companies take advantage of this misconception by packaging and positioning their products as dental care products. A laboratory test of five samples of red tooth powder that did not declare tobacco as an ingredient found a tobacco content of 9.3-248 mg per gram of tooth powder.

The 1992 amendment to India's Drugs and Cosmetics Act 1940 barred manufacturers from using tobacco as an ingredient in any toothpaste or toothpowder. One manufacturer challenged this amendment, but ultimately the Supreme Court passed judgment in favour of the government of India. ${ }^{1}$

We carried out our study 10 years after the law had been amended. Surprisingly, 6-68\% students still reported that they currently used products containing tobacco for oral care, which shows clearly that the regulations have not been implemented adequately.

This study was carried out in technical collaboration with the US Centers for Disease Control. The global youth tobacco survey in Maharashtra was done by Surendra Shastri and in Goa by the late S G Vaidya, and we are grateful for their permission to use their data. We wish to acknowledge the contribution and help from Samira Asma and Charles Warren.

Contributors: DNS conducted fieldwork in 12 of the 14 states included in this study and wrote the first draft. PCG coordinated the fieldwork in all these states, interpreted the results, and wrote the final version of the report. MSP handled the datasets and conducted data analysis. PCG is the guarantor

Funding: Tobacco Free Initiative, World Health Organization. Competing interests: None declared.

Ethical approval: The study design was evolved and approved by the World Health Organization in Geneva, Switzerland, and the Centers for Disease Control and Prevention in Atlanta, USA. The surveys were conducted with their collaboration. The study satisfied ethical criteria specified by the Indian Council of Medical research. Appropriate permission from the state education authority and the principal of each school was obtained. The study design did not fall within the scope of studies that require clearance by the internal review board of the Tata Memorial Hospital. The other institutions do not have their own internal review boards.

Simpson D. India: tobacco toothpaste squeezed out. Tobacco Control 1997;6:171-4.

2 Sinha DN, Gupta PC, Pednekar MS. The global youth tobacco survey in north eastern states in India. Indian J Cancer (in press).

Bhonsle RB, Murti PR, Gupta PC. Tobacco habits in India. In: Gupta PC, Hamner JE, Murti PR, eds. Control of tobacco-related cancers and other diseases. Proceedings of an International Symposium, 1990. Bombay: Oxford University Press, 1992.

4 The Global Youth Tobacco Survey Collaborative Group. Tobacco use among youth: a cross country comparison. Tobacco Control 2002;11:25270 .

5 Global Youth Tobacco Survey Collaborating Group. Differences in worldwide tobacco use by gender: findings from the global youth tobacco survey.J Sch Health 2003;73:207-15.

(Accepted 3 October 2003)
Department of Family Medicine, Samsung Medical Center,

SungKyunKwan University School of

Medicine, 50

Irwon-Dong,

Gangnam-Gu,

Seoul, Korea

Yun-Mi Song

epidemiologist

continued over

BMJ 2004;328:324-5

\section{Blood pressure, haemorrhagic stroke, and ischaemic stroke: the Korean national prospective occupational cohort study}

Yun-Mi Song, Joohon Sung, Debbie A Lawlor, George Davey Smith, Youngsoo Shin, Shah Ebrahim

Deaths from haemorrhagic stroke declined consistently through the 20th century, but deaths from ischaemic stroke showed a rise and fall, mirroring the coronary heart disease epidemic. ${ }^{1}$ Blood pressure has also declined, ${ }^{2}$ and if blood pressure is more strongly associated with haemorrhagic stroke than with ischaemic stroke, this might contribute to the divergent trends. Previous meta-analyses have shown contradictory findings; one showed similar associations for both stroke subtypes, ${ }^{3}$ and another, of Asian studies, showed a stronger association with haemorrhagic stroke than with ischaemic stroke. ${ }^{4}$ To resolve this uncertainty, we examined the association of blood pressure with subtype of stroke in a large cohort of Korean civil servants.

\section{Participants, methods, and results}

The Korean National Health System for public servants and teachers provides medical expenses and biennial multiphasic health examinations at which blood pressure is measured in the seated position by trained staff using a standard mercury sphygmomanometer (fifth Korotkoff sound used for diastolic pressure) or an electronic manometer. ${ }^{5}$ We grouped mean blood pressures for individuals between 1986 and 1996 according to the joint national committee on prevention, detection, and treatment of high blood pressure categories of normal, stages 1, 2, and 3 (table). We included deaths attributed to ICD-10 (international classification of diseases, 10th revision) codes of I60-I69 for all strokes, I61 for haemorrhagic stroke, 